\title{
A Network of Pathways Controlling Cellular Homeostasis Affects the Onset of Senescence in Podospora anserina
}

\author{
Heinz D. Osiewacz * (D) and Lea Schürmanns \\ Institute for Molecular Biosciences, Faculty of Biosciences, Goethe University, Max-von-Laue-Str. 9, \\ 60438 Frankfurt, Germany; schuermanns@bio.uni-frankfurt.de \\ * Correspondence: osiewacz@bio.uni-frankfurt.de
}

Citation: Osiewacz, H.D.;

Schürmanns, L. A Network of Pathways Controlling Cellular Homeostasis Affects the Onset of Senescence in Podospora anserina. J. Fungi 2021, 7, 263. https://doi.org/ $10.3390 /$ jof7040263

Academic Editor: Ulrich Kück

Received: 11 March 2021

Accepted: 28 March 2021

Published: 31 March 2021

Publisher's Note: MDPI stays neutral with regard to jurisdictional claims in published maps and institutional affiliations.

Copyright: (c) 2021 by the authors. Licensee MDPI, Basel, Switzerland. This article is an open access article distributed under the terms and conditions of the Creative Commons Attribution (CC BY) license (https:/ / creativecommons.org/licenses/by/ $4.0 /)$.

\begin{abstract}
Research on Podospora anserina unraveled a network of molecular pathways affecting biological aging. In particular, a number of pathways active in the control of mitochondria were identified on different levels. A long-known key process active during aging of P. anserina is the agerelated reorganization of the mitochondrial DNA (mtDNA). Mechanisms involved in the stabilization of the mtDNA lead to lifespan extension. Another critical issue is to balance mitochondrial levels of reactive oxygen species (ROS). This is important because ROS are essential signaling molecules, but at increased levels cause molecular damage. At a higher level of the network, mechanisms are active in the repair of damaged compounds. However, if damage passes critical limits, the corresponding pathways are overwhelmed and impaired molecules as well as those present in excess are degraded by specific enzymes or via different forms of autophagy. Subsequently, degraded units need to be replaced by novel functional ones. The corresponding processes are dependent on the availability of intact genetic information. Although a number of different pathways involved in the control of cellular homeostasis were uncovered in the past, certainly many more exist. In addition, the signaling pathways involved in the control and coordination of the underlying pathways are only initially understood. In some cases, like the induction of autophagy, ROS are active. Additionally, sensing and signaling the energetic status of the organism plays a key role. The precise mechanisms involved are elusive and remain to be elucidated.
\end{abstract}

Keywords: aging; autophagy; homeostasis; mitochondria; peroxisomes; Podospora anserina; quality control; signaling

\section{Introduction}

Podospora anserina is a filamentous fungus that, in contrast to most other fungi, is characterized by a defined limited lifespan. Already in the 1950s it was reported that this ascomycete develops a well-defined senescence syndrome [1]. Depending on the strain, this syndrome occurs after a defined short period of growth (e.g., after 2-3 weeks): the pigmentation of the peripheral part of the thallus increases while the growth rate decreases until it comes to a complete stop and the thallus dies at the growth front. Subsequently, this phenotype was carefully investigated and it turned out to be under the control of environmental and genetic factors. Both nuclear as well as extranuclear genetic traits are active [2-4]. Later on, it was demonstrated that a genetic element located in mitochondria accumulates as a plasmid-like covalently closed circular DNA (plDNA). It behaves like a mobile element and gives rise to gross reorganization of the standard mitochondrial DNA (mtDNA). As a consequence, large parts of the mtDNA with a number of essential genes are deleted leading to deficiencies in mitochondrial biogenesis and function and death of the thallus at the hyphal tips [5-9].

Since this time, senescence in P. anserina was carefully analyzed and the fungus became a well-established model system in experimental aging research [10-12]. In particular, the analyses of a number of mutants, which live longer than the wild type, provided important 
clues and revealed insights into the mechanisms of lifespan control. This work unraveled a paramount role of mitochondria and of the cellular energy metabolism. One group of mutants (ex and mex) contained deletions of parts of the PaCoxI gene and, thus, an essential component of complex IV of the respiratory chain is ablated. In these mutants the expression of a nuclear gene coding for an alternative oxidase (PaAOX) is induced and respiratory deficiency is rescued [13,14]. As a consequence, the corresponding mutants are long-lived. The molecular basis of this example of mitochondrial-nuclear interactions, which requires signaling from impaired mitochondria to the nucleus and the activation of $P a A o x$-specific transcription factors [15], became clear via the analysis of other mutants and uncovered an impact of ROS (for more details see below).

Subsequently, a number of different molecular pathways, involved in the control of cellular homeostasis, were identified which are effective in keeping the individual thallus functional over a longer period of time. However, when impairments accumulate beyond rescue limits, programmed cell death (PCD) [16] is induced and the thallus dies at the hyphal tips. PCD was found to be controlled by various factors like "apoptosis inducing factors" (AIFs) [17] and the activation of the two calcium-dependent metacaspases PaMCA1 and PaMCA2 [18-20]. During this process, the opening of a mitochondria transition pore (mPTP) plays a key role [21-23].

In this review, we focus on the network of interacting pathways and include recent studies that provide new perspectives to unravel the role of cellular homeostasis in aging and lifespan control of P. anserina in more detail. We put special emphasis on the bioenergetic role of mitochondria and include some ongoing work on the potential impact of mitochondrial ultrastructure regulation and on peroxisomes which, like mitochondria, are involved in the control of cellular energy metabolism. From these studies, it is clear that pathways controlling the quality and quantity of these organelles are crucial for cellular homeostasis. The involved pathways act at different cellular stages and need to be well coordinated by signal transduction pathways.

\section{Generation, Balancing of Cellular Levels and Role of Reactive Oxygen Species}

Previous research on mutants with a lifespan differing from that of the wild type was instrumental in the elaboration of mechanisms involved in the control of P. anserina aging and lifespan. Among the various long-lived mutants investigated, the grisea mutant, in which the nuclear encoded gene for the GRISEA transcription factor is not expressed due to a mutation in the single intron of this gene, provided a number of relevant data to understand the relevance of mitochondrial respiration. The grisea mutant is a copperuptake mutant leading to deficiency in complex IV of the respiratory chain the function of which depends on the availability of copper as a cofactor. In this mutant, like in the mentioned ex mutants, the expression of PaAox is induced [24-26].

The grisea mutant is long-lived and respires via an alternative respiration chain, bypassing complex III and IV of the respiratory chain (Figure 1). As a consequence, the formation of the superoxide anion (hereafter superoxide) is lower in the corresponding mutant. A disproportion reaction catalyzed by a superoxide dismutase (SOD) leads to hydrogen peroxide, a ROS that is able to pass the phospholipid bilayer of membranes and acts in the different cellular compartments. Hydrogen peroxide can be transformed to water via the activity of catalases, peroxidases or, in the presence of copper (I) or iron (II) $\left(\mathrm{Cu}^{+}\right.$, $\mathrm{Fe}^{2+}$ ), can give rise to the formation of the hydroxyl radical for which no decomposition enzyme exists (Figure 2). This free radical is highly toxic and, together with the other ROS, causes damage to all kinds of cellular components like proteins, nucleic acids, and lipids. However, ROS (i.e., hydrogen peroxide) are also essential for cellular activities because, at low concentrations, they act as signaling molecules. Due to this dual function, it is essential to carefully balance cellular ROS levels which is achieved by controlling the generation of ROS and by scavenging them. Different components, enzymes, as well as nonenzymatic antioxidants (e.g., vitamins $C$ and E, carotinoids, flavonoids, or polyamines), are involved in these processes [27-35]. 
Standard Respiration

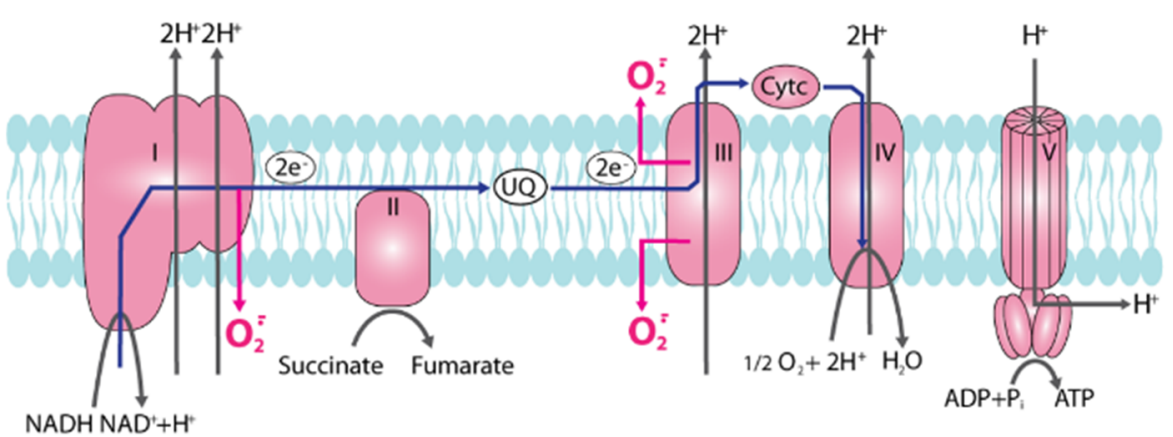

Alternative Respiration

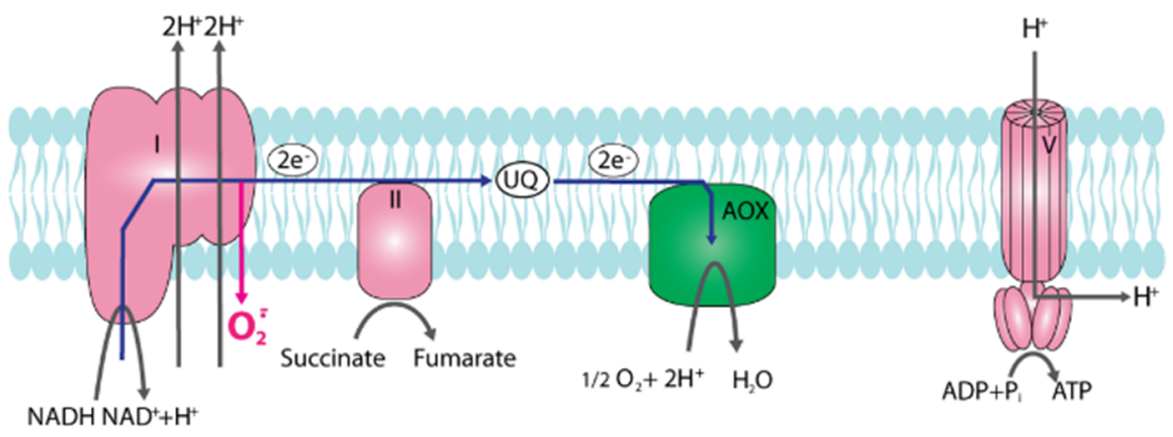

Figure 1. Scheme indication electron and proton flow in and through the inner mitochondrial membrane. Both, standard cytochrome c oxidase (IV) and alternative oxidase (AOX) dependent respiration are indicated. Standard respiration releases superoxide to both, the intermembrane space and the mitochondrial matrix. During alternative oxidation, superoxide is only released to the matrix at complex I. Since less protons are pumped to the intermembrane space via alternative respiration, the generated electron motive force is lower than at that of standard respiration and less ATP is generated at the $\mathrm{F}_{\mathrm{o}} \mathrm{F}_{1}$-ATP-synthase $(\mathrm{V})$.

As mentioned above, in heterotrophic eukaryotes a main site of ROS generation are mitochondria. The primary ROS is the superoxide free radical and mainly produced at complex I and III of the standard respiratory chain. At those complexes, superoxide molecules are released to the mitochondrial matrix, and at complex III to the intermembrane space as well (Figure 2). Due to its negative charge, superoxide is not able to cross biomembranes directly through the phospholipid bilayer. However, it can be released from the intermembrane space to the cytoplasm via anion channels (porins) in the outer mitochondrial membrane [36].

In one P. anserina study, it was demonstrated that respiration via the copper-independent alternative pathway results in a strongly reduced generation of superoxide, explaining the increased lifespan as a result of a reduction in ROS-induced molecular damaging [37]. This explanation can also be applied to other mutants which respire via the alternative oxidase $[14,38]$. As a consequence of by-passing complex III and IV of the respiratory chain, which are proton pumping membrane complexes, the electromotive force generated at the inner mitochondrial membrane is lower in mutants respiring via PaAOX than in strains using the standard PaCOX-dependent pathway and therefore less ATP is generated at the $\mathrm{F}_{\mathrm{o}} \mathrm{F}_{1}$-ATP-synthase (complex V). The derived differences in the energetic status are responsible for the observed reduction in growth rate and impairments in the formation of female gametangia $[14,25,38]$. Although not analyzed in detail, sensing (i.e., the AMP/ATP ratio) and signaling of the energy status by "AMP-activated kinase" (AMPK), a central sensor and regulator of the cellular nutrient status, is involved in the underlying molecular pathways (Figure 2). 


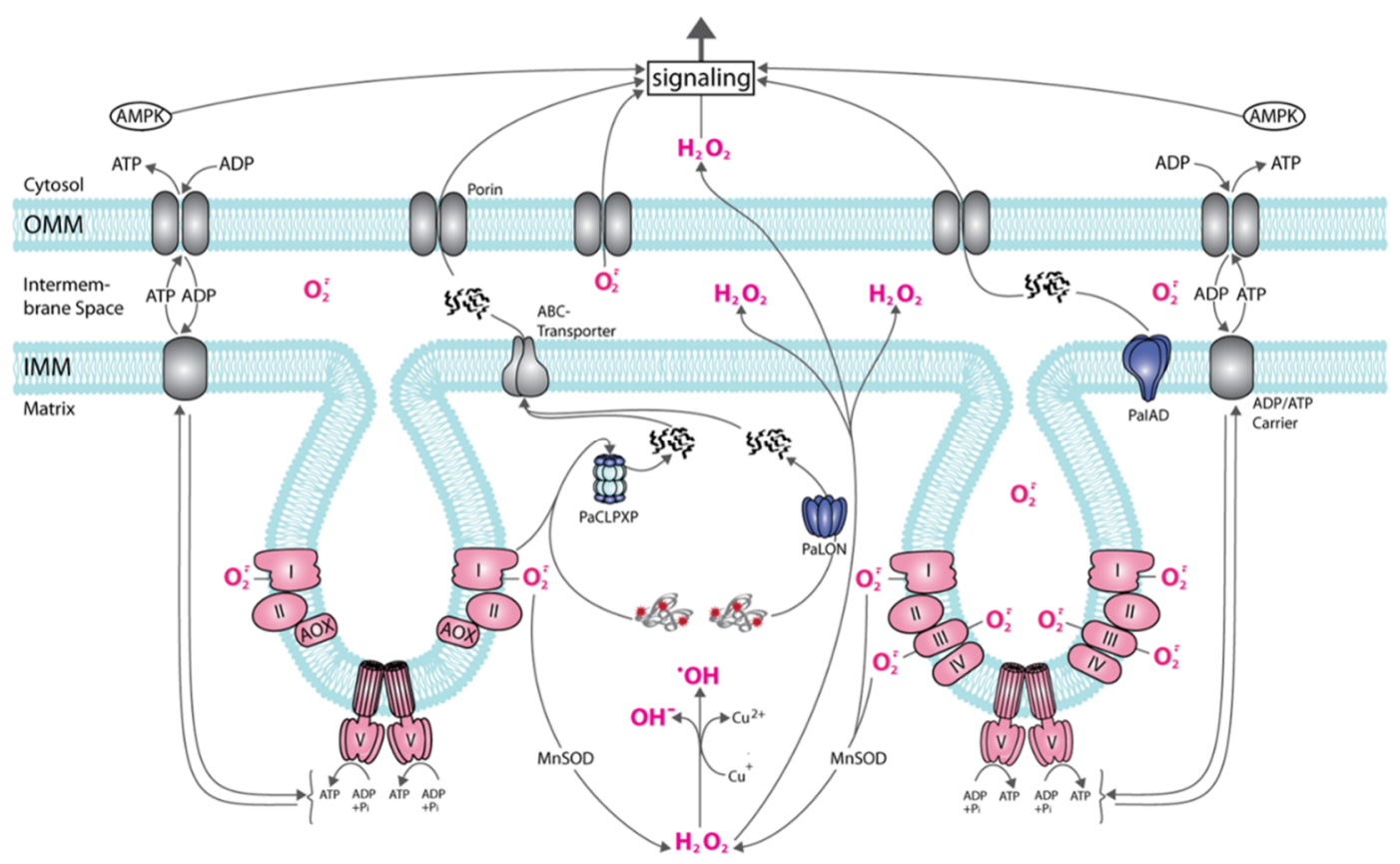

Figure 2. Age-related mitochondrial signaling in P. anserina. The scheme shows a part of a mitochondrion with two cristae formed by the invagination of the inner mitochondrial membrane (IMM). On the right, the standard respiratory chain is part of the IMM, on the left, the alternative respiratory chain with the alternative oxidase (AOX) is displayed. To note: at the standard respiratory chain superoxide is released into the inner space of cristae and into the matrix, at the alternative respiratory chain only into the matrix. In the matrix, superoxide $\left(\mathrm{O}^{-} \cdot\right)$ can be transformed into hydrogen peroxide $\left(\mathrm{H}_{2} \mathrm{O}_{2}\right)$ that, in the presence of $\mathrm{Cu}$ (I) or Fe (II) (for simplicity only $\mathrm{Cu}$ (II) is shown) can form the highly toxic hydroxyl radical $(\cdot \mathrm{OH})$ or can pass the IMM and outer membrane (OMM) phospholipid layer reaching the cytosol. Superoxide in the intermembrane space can be released to the cytoplasm via porins. Damaged (red asterisks) or excessive proteins can be degraded by PaLON, PaCLPXP, PaIAP, or other proteases (not shown) to peptides that can be transported to the cytosol and are effective in the induction of responses. The energetic status (AMP/ATP ratio) of the cell can be sensed by AMPK and induces a variety of molecular responses.

The effect of ROS scavenging on P. anserina was investigated in several studies. One series of studies analyzed the effect of the modulation of PaSOD3 levels, a manganesedependent mitochondrial SOD (MnSOD). The abundance of this isoform was found to decline during aging [22]. Surprisingly, the overexpression of the corresponding gene did not result in lifespan extension but in a decreased lifespan and resistance against hydrogen peroxide [35]. In the mutant, it was found that several enzymes involved in cellular quality control were affected. These effects turned out to result from the increased generation of hydrogen peroxide by the increased abundance of PaSOD3 in the overexpressor [30,39].

In another series of studies PaMTH1, a protein encoded by a nuclear gene, was identified to accumulate during aging and turned out to be an S-adenosylmethionine-dependent methyltransferase $[22,29,40]$. During aging the protein is imported into mitochondria. PaMTH1 is able to methylate flavonoids with vicinal hydroxyl groups, which are prone to produce ROS in the presence of iron or copper [31,41]. The methylation of these groups via PaMTH1 thus prevents ROS generation by these compounds. In accordance with this function, overexpression of $\mathrm{PaMth1}$ leads to a protection of proteins against oxidation and an increase in lifespan [32,42].

Overall, the data demonstrate a damaging effect of ROS contributing to degeneration of P. anserina cultures. Processes leading to well-balanced levels of ROS are effective in the control of cellular homeostasis and act as pro-survival mechanisms. 


\section{Repair and Degradation of Cellular Components}

\subsection{Stabilization of mtDNA and Mitochondrial Base Excision Repair}

Apart from pathways active in balancing the generation and scavenging of ROS preventing damage of cellular components, mechanisms evolved which repair damaged molecules or, if this is not possible, degrade them and resynthesize new and functional ones. The control of the integrity of DNA is well investigated in many biological systems in great detail. As mentioned, the mtDNA of P. anserina becomes greatly rearranged during aging. In this process, the first intron of the $\mathrm{PaCoxI}$ gene plays a key role which, after liberation and formation of plDNA, acts as a mutator via the induction of age-related mtDNA rearrangements $[6-8,43]$. In a first step, plDNA integrates either into a position directly downstream of the pl-intron in PaCoxI ("homing-like" transposition) or into other sites in the mtDNA ("ectopic" transposition). Thus, two intron copies are present in a single mtDNA molecule. Homologous recombination between these sequences may lead to the amplification of pIDNA or of larger mtDNA circles. Those circles containing no origin of replication are subsequently lost. Significantly, although not formally proven, a protein with reverse transcriptase activity encoded by the pl-intron may be involved in transposition processes [44]. The described scenario is supported by various experimental data. For instance, in strains in which the pl-intron is deleted (e.g., ex and mex mutants) the mtDNA is stabilized $[13,14]$. Or, in the long-lived mutant AL2-1, the processes leading to the amplification of plDNA are delayed. This delay is linked to the presence of the linear plasmid pAL2-1, which encodes an RNA and DNA polymerase [45-47].

Apart from the processes counteracting gross mtDNA reorganizations, repair of subtle mutations is possible and likely to affect aging in P. anserina. In one study, a decrease of base excision repair (BER) activity was reported during aging of $P$. anserina. For one enzyme of BER, DNA glycosylase, activity was found to be higher in long-lived mutants with a lower ROS burden [48].

\subsection{Degradation of Damaged Molecules and of Excess Components}

During the lifespan of any organism, all kinds of cellular components change in quality and quantity. For instance, due to molecular stress (e.g., oxidative stress, heat stress) proteins may be oxidized or may aggregate and become impaired in function. Or, due to exogenous (e.g., nutrient deprivation) or endogenous conditions (e.g., developmental stages) their abundance needs to be adopted. This situation requires a dynamic system in which damaged or excess components can be degraded and, if necessary, be resynthesized again. In P. anserina, different pathways were shown to be active and have a significant impact on lifespan.

\subsubsection{Proteases}

One series of studies were dealing with naturally occurring processes active in controlling cellular protein quality. These proteases degrade their substrate proteins to peptides which, via membrane protein complexes (e.g., ABC transporters, porins), are released from mitochondria to the cytoplasm and give rise to signaling (Figure 2) $[49,50]$. Here a great impact of mitochondrial proteases on lifespan control and senescence of $P$. anserina was uncovered. For instance, two complementary studies uncovered the role of the PaLON, the mitochondrial matrix LON protease of $P$. anserina. In a strain overexpressing PaLon, the abundance of carbonylated proteins (i.e., mitochondrial aconitase) was found to be decreased. No effects on vital functions like fertility or growth rate were observed demonstrating an increase of the healthy period of time, the healthspan, in the lifespan of the fungus [51]. In contrast, deletion of PaLon retarded growth and led to lifespan reduction [52]. Another mitochondrial protease is PaIAP, which is an ATP-dependent protease in the inner mitochondrial membrane. From studies in yeast and Neurospora crassa it is known that this protease is involved in the degradation of inner membrane proteins (e.g., cytochrome oxidase subunit 2, prohibitins 1 and $2[53,54]$ ). Deletion of Palap resulted in an unexpected pronounced lifespan extension. More detailed analysis uncovered that 
this lifespan extension occurs when cultures are grown at standard laboratory temperature of $27^{\circ} \mathrm{C}$. At temperatures of $37^{\circ} \mathrm{C}$ spore germination and fruiting body development were affected and lifespan was decreased [55]. It appears that PaIAP is part of a flexible system allowing survival under changing temperature conditions as they appear in nature.

Yet another mitochondrial protease is PaCLPP which forms a multiprotein complex with PaCLPX (Figure 2). The PaCLPXP complex consists of two hexameric rings of PaCLPP forming the proteolytic chamber in which proteins are cleaved to peptides. This part of the complex interacts with one or two hexameric rings of PaCLPX, acting as chaperones and introducing the proteins to be degraded into the proteolytic chamber. Thus, the complex, which is located in the mitochondrial matrix, structurally resembles the cytoplasmic proteasome.

The function of the eukaryotic CLPXP complex is currently only initially elaborated. In the nematode Caenorhabditis elegans the protease was demonstrated to be involved in the control of the mitochondrial unfolded protein response [56]. In P. anserina, evidence derived from a stringent substrate-trapping assay provided compelling evidence for a key role of PaCLPXP in controlling the mitochondrial energy metabolism [57]. Among the identified 19 high confident substrates, there were proteins of the pyruvate dehydrogenase complex, the Krebs cycle and the respiratory chain [57]. Some overlapping proteins were later also found in mammals and Arabidopsis thaliana. In particular, components of the N-module of complex I of the respiratory chain appear to be conserved substrates of CLPXP [58-60].

Surprisingly, in P. anserina, the deletion of the genes coding for $\mathrm{PaClpP}$ as well as $\mathrm{PaClpX}$ let to a pronounced extension of the lifespan. In addition, the double mutant is long-lived. In this mutant mitochondrial respiration is affected: oxygen consumption experiments revealed a general decline of respiration. In comparison to the wild type, the double deletion strain displays a significant increase in alternative respiration. Unexpectedly, ATP content was not changed in the double mutant [61]. The mutant phenotype of the PaClpP deletion strain was rescued to wild-type characteristics by the expression of the human $C l p P$ gene identifying a conservation of the proteins from the two evolutionarily-distant species $[61,62]$.

The $26 \mathrm{~S}$ proteasome, although not located in mitochondria, was previously demonstrated to be active in the degradation of mitochondrial proteins via "mitochondriaassociated degradation" (MAD) [63]. Moreover, research on mammalian cell culture or centenarians revealed a link between high proteasome activity and long lifespan [64,65]. An attempt to identify a potential role of the ubiquitin proteasome system (UPS) in aging of P. anserina, an age-related analysis of transcripts and proteins of specific components of the P. anserina proteasome were studied. No age-related differences in abundance were found. Moreover, a study using Gfp-Cl1 transgene coding for the CL1 degron sequence fused to GFP, led to the interesting observation that after heat stress this potential substrate of the proteasome localized to the vacuole. In western blot experiments, the fusion protein was partly degraded leaving its GFP portion stably retained. Overall, this specific approach did not reveal evidence for the expected function of the UPS in quality control of the CL1 degron as a proteasomal substrate in P. anserina but instead suggested an efficient role of basal autophagy, the vacuolar degradation of proteins [66]. A role of autophagy in the control of aging was further suggested by a genome-wide transcriptome analysis of the P. anserina wild type. In this study, it was found that transcripts coding for the proteasomal subunits decreased in abundance at later stages in the lifespan while transcripts of the autophagic machinery increased [67] indicating that autophagy takes over quality control functions from the UPS in particular in older age. A later analysis basically verified this observation on the protein level but in addition identified that autophagy first increases in later age but finally decreases in very old age, in stages that were not investigated in the transcriptome analysis due to technical limitations $[61,68]$. 


\subsubsection{Vacuolar Degradation}

First experimental evidence for an increase of macroautophagy, a form of autophagy in which cellular components are delivered via autophagosomes to the vacuole, was observed in a microscopic study investigating the formation of autophagosomes during aging of the P. anserina wild type in which a GFP-ATG8 fusion protein was expressed [69]. Under standard growth conditions on a minimal growth medium no or only few GFP-labeled autophagosomes were visible. In senescent cultures, a larger number of autophagosomes were observed. Moreover, under nitrogen-depleted conditions, under which autophagy is induced, autophagosomes were found to occur already in young cultures. These data verified a role of macroautophagy in the control of aging and the energetic status of $P$. anserina. Significantly, the ablation of PaATG1, a serine/threonine kinase that is essential for the formation of autophagosomes, led to a reduction of the wild-type specific lifespan and identified autophagy as a longevity-assurance pathway. The demonstration of the degradation of cytoplasmic superoxide dismutase 1 (SOD1) and the link to nitrogen starvation suggests that it is non-selective (bulk) autophagy, the degradation of cellular components in a portion of the cytoplasm delivered by autophagosomes to the vacuole, which is active to compensate age-related deficiencies in energy transduction and other impairments (e.g., quality control via UPS) as they appear in older age of P. anserina.

Another example for a compensatory, pro-survival function of autophagy was demonstrated in a PaSod3 deletion mutant. Due to the ablation of the mitochondrial MnSOD (Figure 2), which is involved in mitochondrial superoxide scavenging, it was expected that the mutant is functionally impaired and short-lived. In fact, lifespan did not differ from that of the wild type. This unexpected phenotype was found to dependent on functional autophagy. In the PaSod 3 deletion strain, in contrast to the wild type, autophagy is induced already in young cultures. In addition, the induction of mitophagy, the selective vacuolar degradation of mitochondria, was strongly induced while non-selective autophagy in the mutant did not differ from that in the wild type [68]. Further on, in the same study, the effect of mild paraquat-induced external oxidative stress on the wild type and the PaSod3 deletion strain revealed that addition to the growth medium of $20 \mu \mathrm{M}$ paraquat, that gives rise to extra mitochondrial superoxide generation, had different effects on lifespan in the two strains. The wild type showed a strong increase in lifespan while in the mutant lifespan was decreased. These opposite effects are dependent on a functional autophagic machinery. Overall, these data can be explained by a hormetic (beneficial) effect of mild oxidative stress that is induced in the wild type. In contrast, in the mutant oxidative stress is already higher than in the wild type without the addition of paraquat due to the ablation of PaSOD3. In this situation, additional superoxide generation leads to excessive cellular oxidative stress which leads to autophagy-dependent cell death (ADCD) $[16,68]$. This kind of cell death is also observed in a short-lived mutant in which $P a C y p D$ coding for a peptidyl prolyl-cis, trans-isomerase (CYPD) a regulator of the mitochondrial permeability transition pore (mPTP) is overexpressed. Deletion of $P a C y p D$ leads to a decrease in autophagy in older age of the P. anserina wild type. Moreover, the study also demonstrated that PaCYPD is required for mitohormesis [23].

Taken together, autophagy appears to be a "double-edged sword". Low stress results in hormetic, pro-survival effects of autophagy while excessive stress leads to death of P. anserina cultures via the induction of ADCD. These opposite outcomes can be triggered by exogenous factors. The polyphenol curcumin from Curcuma longa leads to a hormetic induction of autophagy and lifespan extension while the polyphenol gossypol from Gossypium spec leads to ADCD and a decreased lifespan [70,71].

Another example of the capacity to compensate impairments of other components of pathways in the control of cellular homeostasis was observed in the deletion mutants coding for the mitochondrial PaCLPXP complex (Figure 2). Counterintuitively, these mutants are long-lived with a constitutive induction of non-selective autophagy. Significantly, lifespan extension depends on a functional molecular autophagy machinery. Moreover, the relevance of autophagy was underlined by the observation that, in contrast to the wild type, 
autophagy was already induced in early life stages (four-day-old cultures) [61]. Overall, these data indicate intimate interactions of PaCLPXP and autophagy. A common function of non-selective autophagy and of CLPXP is the control of cellular metabolism. This link was further demonstrated in a recent study aimed to further characterize PaCLPXP. In this study the surprising observation was that the deletion of PaSnf1 coding for the catalytic subunit of AMPK led to lifespan extension (Figure 2) [72]. The study revealed that PaSNF1 is required for autophagy, mitochondrial dynamics and respiration. Most surprisingly, the $\mathrm{PaSnf1} / \mathrm{PaClpP}$ double deletion resulted in a synergistic effect with an even longer lifespan than that of the single mutants. The lifespan increasing effect was found to be stronger in strains of the mating type "minus" containing the rmp1-1 allele of the rmp1 gene that is closely linked to the mating-type locus. These data imply the interaction of completely different molecular pathways active in protein quality control, the sensing and control of cellular energy with the poorly characterized RMP1 protein, a protein that is involved in respiratory complex assembly and is likely active in mitochondrial translation $[73,74]$. The coordination of the corresponding pathways is unclear.

The impact of macroautophagy in P. anserina was further demonstrated in a mutant in which PaATG24 was ablated leading to a short-lived phenotype. In addition, growth rate and fertility are affected [75]. PaATG24 is a putative sorting nexin. Members of this evolutionary conserved protein family are involved in vesicle transport, membrane trafficking and protein sorting [76-78]. Deletion of PaAtg24 leads to a changed morphology and size of vacuoles and a reduction of non-selective and selective autophagy. Mitophagy is reduced in the mutant and increases during aging. In contrast, general autophagy and pexophagy, the selective degradation of peroxisomes, is almost completely inhibited in the mutant and does not change during aging. Overall, the data uncovered membrane-regulated pathways involved in autophagy and lifespan regulation. The impact of pexophagy on aging and lifespan control is yet not analyzed but, since this organelle is also involved in energy metabolism and interacts with mitochondria, it is an interesting question whether or not and in how far these organelles are subject to age-related regulation and for biological aging.

\section{Biogenesis and Dynamics of Mitochondria}

Mitochondria are semiautonomous organelles in which most of the approximately $1200-1600$ proteins are encoded by nuclear DNA and only a few by mtDNA. Mitochondria are dynamic and change their morphology and ultrastructure depending on physiological constraints. Mitochondrial mass (size and number of mitochondria) changes during growth and development (Figure 3). This process is not the result of de novo synthesis of the organelle but by the biosynthesis of new components and their integration into existing mitochondria.

During "growth" of mitochondrial units, they form filamentous morphotypes that subsequently can divide into smaller units. These can fuse again to form filamentous organelles. Fission and fusion are genetically controlled by a number of proteins. Additionally, excess or functionally impaired (damaged) mitochondria can be removed by autophagy.

In addition to the processes of mitochondrial quality control discussed above the control of mitochondrial dynamics was demonstrated in P. anserina to have an effect on aging. Deletion of a gene coding for the dynamin-like protein PaDNM1, an essential protein involved in fission of mitochondria, led to an 11-fold increase in mean lifespan. Mitochondria of this strain had an strongly elongated morphology and even formed networks of fused filaments [79]. Only in very old cultures, mitochondria were found to be fragmented. Furthermore, in this strain no signs of typical reorganization of mtDNA found in the wild type occurred and the release of hydrogen peroxide was delayed to very old age. Lifespan extension was linked to an increase in resistance to the induction of programmed cell death. The relevance of $P a D n m 1$ for normal aging of the wild type is indicated by the increased transcription of the gene in old cultures [79]. Computational modeling integrating mitochondrial fission and fusion, ROS stress, and mitophagy revealed 
a positive impact of mitochondrial dynamics in situations when mitochondria are only marginally damaged. In contrast, deceleration of fission and fusion is an advantage to reach a long lifespan when damage of mitochondria passed critical limits [80,81].

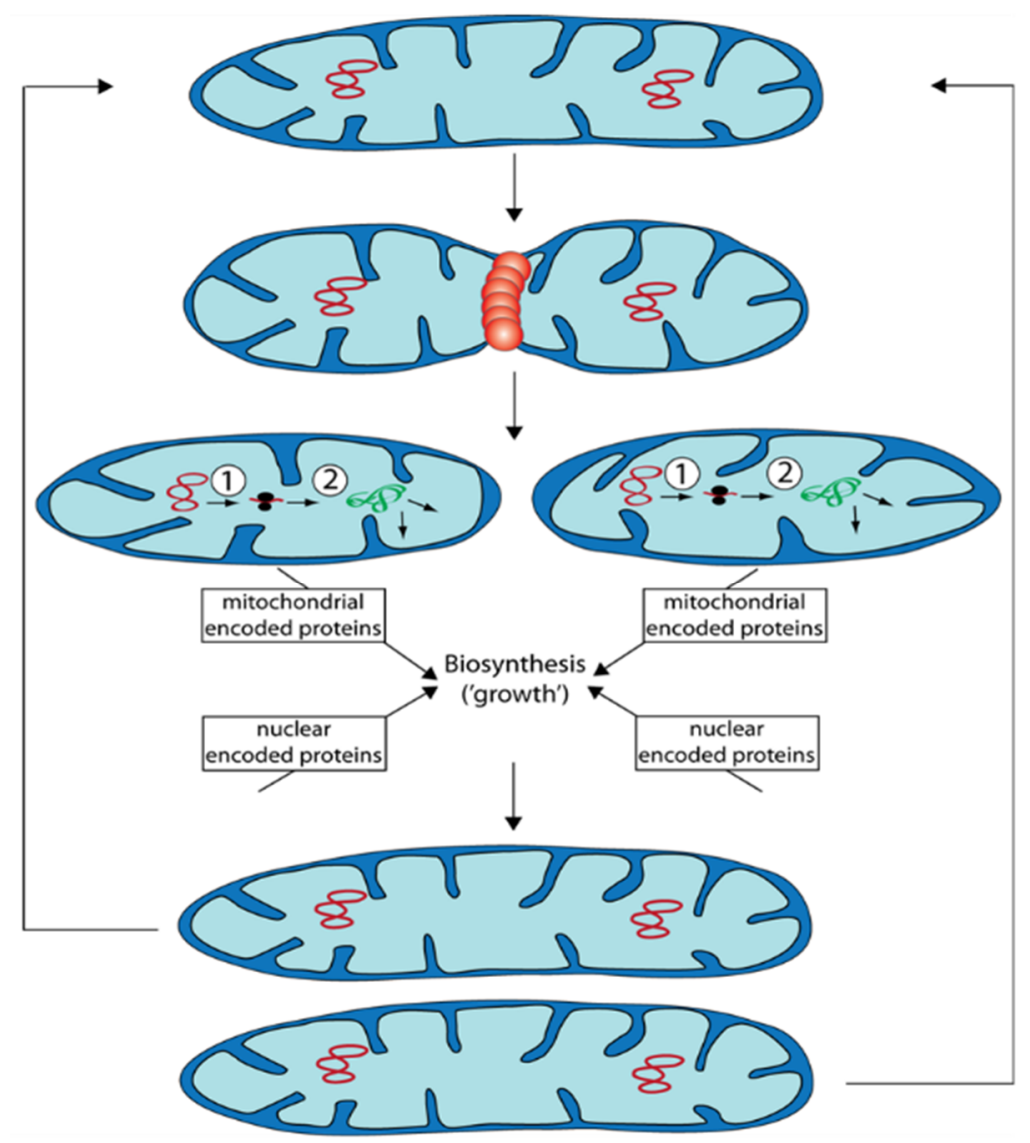

Figure 3. Propagation of mitochondria occurs via fission of prexisting organelles. After fission that is controlled by proteins (e.g., PaDNM1: orange restriction ring), the generated two mitochondria are smaller than the mitochondrion they are derived from. They "grow" depending on protein biosynthesis and on both, mtDNA (red circles) as well as nuclear DNA. Subsequently, they can divide again or they can fuse with other mitochondria. (1): Transcription of mtDNA. (2): Translation of RNA at mitochondrial ribosomes. Proteins (green) are subsequently sorted to the site of their function.

\section{Perspectives}

As discussed above, a hierarchical network of pathways involved in the control of functional mitochondria and energy metabolism and impacts aging and lifespan of P. anserina. It is clear that other, yet not integrated, pathways and cellular compartments are involved in triggering degenerative processes in this species, which, at least in part, may be evolutionary conserved and, therefore, are also relevant in other species including humans.

\subsection{Other Pathways Involved in Mitochondrial Homeostasis}

Yet unexplored, but clearly relevant, are processes leading to mitochondrial biogenesis that are linked to a balanced expression of mitochondrial and nuclear encoded genes and the transport of proteins synthesized in the cytosol $[49,82,83]$. These proteins need to enter mitochondria via a sophisticated protein import machinery and delivered to the different mitochondrial sub-compartments where they have to be properly assembled to functional complexes (e.g., respiratory chain). The various steps of the underlying processes may be prone to age-related impairments and thus are certainly relevant for aging.

Other poorly investigated pathways are pathways that are involved in shaping mitochondrial ultrastructure. Age-related changes were demonstrated by electron cryotomog- 
raphy studies to occur during aging. It was found that the inner mitochondrial membrane changes from a tubular organization of cristae to the formation of vesicular units [84]. Moreover, it was shown that the inner membrane of vesicles at some sites come into contact with the outer membrane. At these sites, breakage of the outer membrane is thought to release mitochondrial vesicles. According to a model, the vesicles finally burst and release mitochondrial content, including mitochondrial copper that is stored in this organelle, into the cytoplasm. Subsequently, released excess copper may lead to the induction of the two metacaspases of P. anserina and finally to the induction of PCD [20]. The details of these processes are yet not formally demonstrated. However, in P. anserina the increase of cytoplasmic copper that may originate from mitochondria was demonstrated [85]. Interestingly, also during aging of human diploid fibroblasts an accumulation of cellular copper was reported [86], suggesting a conservation of molecular copper-related mechanisms.

Yet another factor involved in the typical cristae formation of juvenile mitochondria was demonstrated to be dimers of $\mathrm{F}_{\mathrm{o}} \mathrm{F}_{1}$-ATP-synthase which are involved in curvature formation at the tip of the cristae (see above) $[84,87]$. It remains to be evaluated what finally leads to premature aging of $P$. anserina strains which are impaired in $\mathrm{F}_{\mathrm{o}} \mathrm{F}_{1}$-ATP-synthase.

Another site of membrane curvature is the basic part of cristae, turned cristae junctions are controlled by the "mitochondrial contact site and cristae organization system" (MICOS). During aging and the reorganization of the inner mitochondrial membrane, these large protein complexes necessarily need to change. The impact of these protein complexes on aging has to be evaluated.

Additionally, lipid composition of mitochondrial membranes and the impact on mitochondrial function and aging is unexplored but an emerging field of interest. In particular, the lipid content of inner mitochondrial membrane, which evolved from the endocytosis of $\alpha$-proteobacteria, differs from that of other typical eukaryotic membranes. In particular, the enhanced level of cardiolipin seems to be important. This lipid, a nonbilayer forming phospholipid of conical shape, has been implicated in the formation and stabilization of respiratory supercomplexes, which are more efficient in respiration than a chain of monomer respiratory complexes [88,89]. In this context the pathways involved in the formation of cardiolipin, which is located in the inner mitochondrial membrane, are of considerable interest to be unraveled.

\subsection{Potential Role of Peroxisomes}

In a previous study, investigating the role of PaATG24, it was found that deletion of $\mathrm{PaAtg} 24$ reduces bulk autophagy, mitophagy and pexophagy [75]. Moreover, the number of peroxisomes, which slightly increase during wild-type aging, increases strongly in the short-lived PaAtg24 deletion mutant suggesting a role of peroxisomes in the aging process in P. anserina (Figure 4).

A key function of peroxisomes is to degrade fatty acids via B-oxidation leading to the formation of acetyl-CoA that finally is further metabolized (i.e., in the Krebs cycle in mitochondria). In most organisms, from yeast to humans, during the first step of this process acyl-CoA oxidase performed the oxidation of the fatty acid, which leads to trans$\Delta^{2}$-enoyl-CoA and the formation of hydrogen peroxide as a byproduct. This molecule contributes to the cellular ROS load, to ROS scavenging, signaling, and via unbalanced conditions to molecular damaging.

There is considerable evidence that a disturbance in peroxisomal redox homeostasis affects mitochondrial function and redox balance. For instance, the inactivation of peroxisomal catalase (for more details see above) in human cells results in functionally impaired mitochondria, which lose their ability to maintain a membrane potential and synthesize ROS themselves [90]. On the other hand, it was shown that enhancing the activity of peroxisomal catalase has beneficial effects on mitochondria. It is described that during aging peroxisomal protein import of peroxisomal catalase is becoming particularly impaired [91]. Enhancing the effectivity of catalase import into the peroxisomes, reduces 
cellular hydrogen peroxide levels, as well as the number of senescent cells in a population, and reverses mitochondrial depolarization [92].

(a)
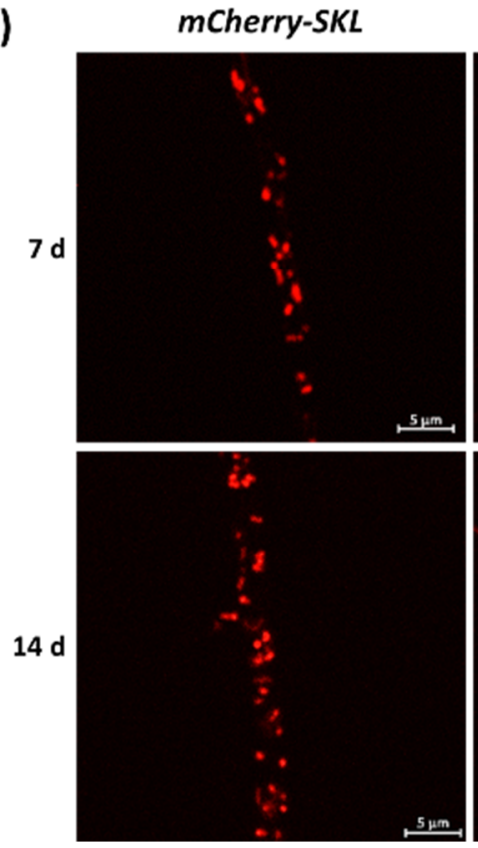

$\triangle P a A t g 24 / m$ Cherry-SKL
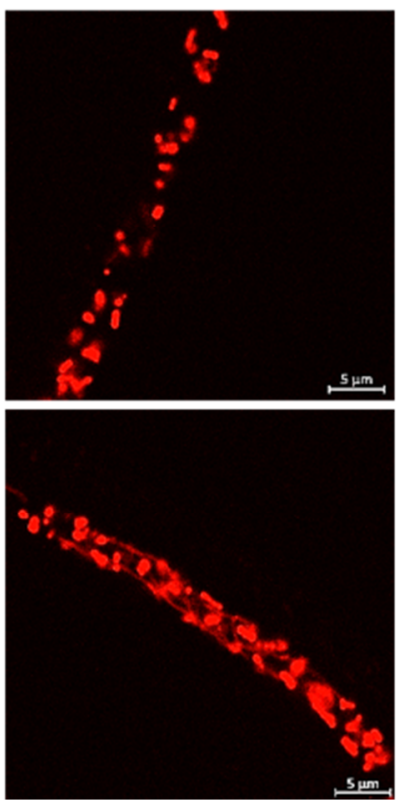

(b)

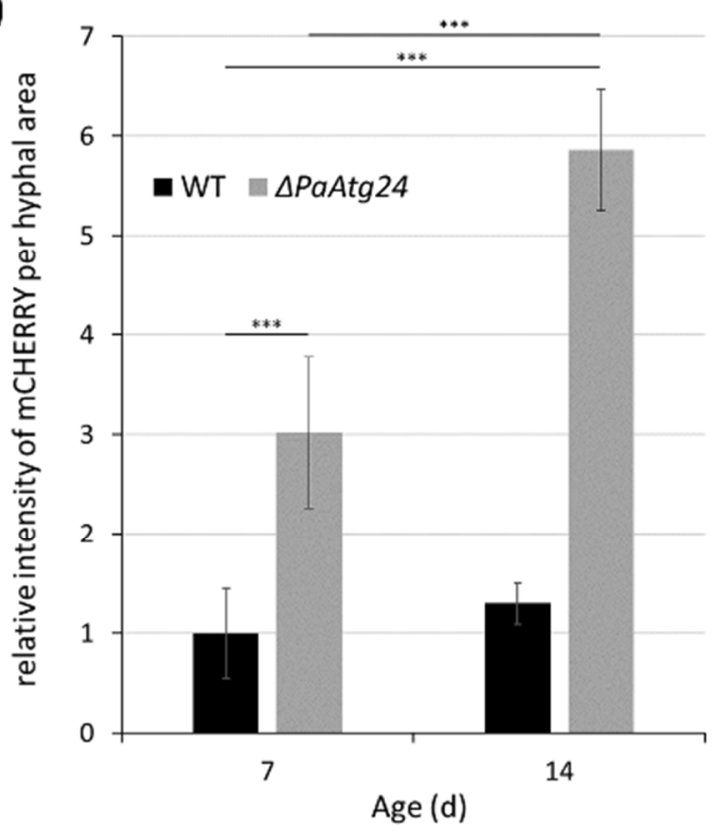

Figure 4. Age-dependent peroxisome abundance in the wild type and the PaATG24 deletion mutant. (a) Fluorescence microscopic analysis of peroxisomes in $\triangle \mathrm{PaAtg} 24$ ( $\triangle \mathrm{PaAtg} 24 / \mathrm{mCherry}$-SKL) and control strain ( $m$ Cherry-SKL) with peroxisomal reporter mCHERRY-SKL in seven- and 14-day-old cultures. Experimental conditions are described in [75]. (b) Quantification of relative intensity of mCHERRY signals per hyphal area. For this analysis $1491.1 \mu \mathrm{m}^{2}$ hyphae of seven-day-old wild type, $1372.3 \mu \mathrm{m}^{2}$ hyphae of 14-day-old wild type, $1433.4 \mu \mathrm{m}^{2}$ hyphae of seven-day-old PaAtg24 deletion mutant, as well as $1436.3 \mu \mathrm{m}^{2}$ hyphae of 14-day-old $\triangle P a A \operatorname{tg} 24(n=3$, each) were analyzed. Error bars correspond to the standard deviation. For statistical analysis, the two-tailed $t$-test was used $(* * * * p \leq 0.001)$.

Interestingly, in some ascomycetous fungi, like N. crassa and P. anserina, no peroxisomal acyl-CoA oxidase was detected. Instead, the enzyme acyl-CoA dehydrogenase was found $[93,94]$, which performs the same reaction as acyl-CoA oxidase but without the production of hydrogen peroxide. Without the production of this ROS, no detoxification system is needed and peroxisomes in $N$. crassa do not contain catalases [95]. In P. anserina the absence of all known catalases (PaCATA, PaCATB, PaCAT2, PaCATP1, and PaCATP2) has no effect on the usability of fatty acids and on the fungus' lifespan [96]. These characteristics identify P. anserina as a great model to study peroxisomal processes beyond the different effects of ROS on the cell and unravel the peroxisomal ROS-independent role of peroxisomes on aging and development. For example, P. anserina is used as a model to study the Zellweger syndrome (also known as cerebro-hepato-renal syndrome). Patients of this hereditary disease cannot build functional peroxisomes. Malformations in the central nervous system, skeleton, liver and kidneys, and other organs, as well as a dramatically reduced lifespan characterize the syndrome [97]. Studies with a P. anserina Pex5 deletion strain unraveled massive impairments of developmental processes leading to a strong reduction of the produced number of fruiting bodies. Interestingly, the morphology of mitochondria is also changed. While functional mitochondria of the wild type are described to be filamentous, the mutant shows round shaped and often aggregated mitochondria [98], which is a strong hint for interactions of mitochondria and peroxisomes. Such interactions are further supported by the fact that mitochondria and peroxisomes are both very dynamic organelles which partly use identical or homologous control elements. For instance, peroxisomal and mitochondrial fission both are controlled by the dynamin-related protein 1 (DNM1) [99,100]. In addition, for peroxisomes a DNM1-independent pathway mediated by 
the dynamin-related protein VPS1 is described [101]. However, in contrast to mitochondria, peroxisome biogenesis can occur also de novo from the endoplasmatic reticulum (ER) by sorting of peroxisomal membrane proteins to a specific region of the ER, from where pre-peroxisomal vesicles bud off. Afterwards peroxisomal matrix proteins are imported (for a current review see [102]).

Another similarity of mitochondria and peroxisomes is the use of isoforms of the LON protease that is responsible for degrading proteins damaged by oxidation. The activity of LON plays a critical role in maintaining function in both mitochondria and peroxisomes, because of its important role in removing oxidatively modified proteins and preventing their accumulation (reviewed in [103]). The role of peroxisomal LON in P. anserina is yet unclear but interesting, since $P$. anserina peroxisomes do not produce hydrogen peroxide during B-oxidation and consequently oxidation of proteins may not be a critical issue in this species.

Since peroxisomes, in contrast to mitochondria, do not contain DNA or a gene expression machinery, all peroxisomal proteins are encoded by the nucleus. Peroxisomal proteins, which are synthesized in the cytoplasm, need to be properly transported to the site of their function in the peroxisomal membrane or the peroxisomal matrix. Thus, a protein import machinery is crucial for proper function of peroxisomes. In P. anserina, it has been shown that the absence of such proteins result in a variety of different impairments. For instance, the absence of PaPEX2 leads to a block of sexual development at the dikaryotic stage. Consequently, ascospore formation is blocked and the corresponding mutant strains are sterile [104]. In addition, it is known that peroxisomal dynamics are tightly regulated during the sexual development of the fungus. In the course of ascospore maturation, the number of peroxisomes decreases dramatically [105]. The observed elimination of peroxisomes is speculated to result from pexophagy. These data are linked to a recent study emphasizing a key role of pexophagy in the regulation of proper peroxisome numbers at different stages in the life of P. anserina [75]. The precise mechanisms involved in this regulation are yet not known but are a key focus of studies aimed to unravel the role of peroxisomes in aging and development.

Author Contributions: Conceptualization: H.D.O., writing and editing: H.D.O. and L.S., experimental work: L.S. All authors have read and agreed to the published version of the manuscript.

Funding: The work of H.D.O. was continuously supported by grants of the Deutsche Forschungsgemeinschaft (DFG, German Research Foundation). Recent work on autophagy was supported by Project-ID 259130777-SFB1177 to H.D.O.

Institutional Review Board Statement: Not applicable.

Informed Consent Statement: Not applicable.

Data Availability Statement: Original data from Figure 4 are available upon reasonable request from the corresponding author.

Acknowledgments: We wish to thank V. Papanikolaou for the careful production of Figures 1-3.

Conflicts of Interest: The authors declare no conflict of interest.

\section{References}

1. Rizet, G. Sur l'impossibilité d'obtenir la multiplication végétative ininterrompue et illimitée de l'ascomycète Podospora anserina. C. R. Hebd. Seances Acad. Sci. 1953, 237, 838-840.

2. Esser, K.; Keller, W. Genes inhibiting senescence in the ascomycete Podospora anserina. Mol. Gen. Genet. 1976, 144, 107-110. [CrossRef] [PubMed]

3. Marcou, D. Notion de Longévité et Nature Cytoplasmique du Déterminant de la Sénescence chez Quelques Champignons; Masson: Paris, France, 1962; pp. 653-764.

4. Marcou, D.; Schecroun, J. La sénescence chez Podospora pourrait etre due à des particules cytoplasmiques infectantes. C. R. Hebd. Seances Acad. Sci. 1959, 248, 280-283.

5. Cummings, D.J.; Belcour, L.; Grandchamp, C. Mitochondrial DNA from Podospora anserina. II. Properties of mutant DNA and multimeric circular DNA from senescent cultures. Mol. Gen. Genet. 1979, 171, 239-250. [CrossRef] 
6. Kück, U.; Osiewacz, H.D.; Schmidt, U.; Kappelhoff, B.; Schulte, E.; Stahl, U.; Esser, K. The onset of senescence is affected by DNA rearrangements of a discontinuous mitochondrial gene in Podospora anserina. Curr. Genet. 1985, 9, 373-382. [CrossRef]

7. Kück, U.; Stahl, U.; Esser, K. Plasmid-like DNA is part of mitochondrial DNA in Podospora anserina. Curr. Genet. 1981, 3, 151-156. [CrossRef] [PubMed]

8. Osiewacz, H.D.; Esser, K. The mitochondrial plasmid of Podospora anserina: A mobile intron of a mitochondrial gene. Curr. Genet. 1984, 8, 299-305. [CrossRef]

9. Stahl, U.; Lemke, P.A.; Tudzynski, P.; Kück, U.; Esser, K. Evidence for plasmid like DNA in a filamentous fungus, the ascomycete Podospora anserina. Mol. Gen. Genet. 1978, 162, 341-343. [CrossRef]

10. Osiewacz, H.D.; Hamann, A.; Zintel, S. Assessing organismal aging in the filamentous fungus Podospora anserina. Methods Mol. Biol. 2013, 965, 439-462. [CrossRef]

11. Osiewacz, H.D.; Stumpferl, S.W. Metabolism and aging in the filamentous fungus Podospora anserina. Arch. Gerontol. Geriatr. 2001, 32, 185-197. [CrossRef]

12. Scheckhuber, C.Q.; Osiewacz, H.D. Podospora anserina: A model organism to study mechanisms of healthy ageing. Mol. Genet. Genom. 2008, 280, 365-374. [CrossRef] [PubMed]

13. Belcour, L.; Begel, O.; Keller, A.M.; Vierny, C. Does senescence in Podospora anserina result from instability of the mitochondrial genome? In Mitochondrial Genes; Slonimski, P., Borst, P., Attardi, G., Eds.; Cold Spring Harbor: New York, NY, USA, 1982; pp. 415-421.

14. Schulte, E.; Kück, U.; Esser, K. Extrachromosomal mutants from Podospora anserina: Permanent vegetative growth in spite of multiple recombination events in the mitochondrial genome. Mol. Gen. Genet. 1988, 211, 342-349. [CrossRef]

15. Sellem, C.H.; Bovier, E.; Lorin, S.; Sainsard-Chanet, A. Mutations in two zinc-cluster proteins activate alternative respiratory and gluconeogenic pathways and restore senescence in long-lived respiratory mutants of Podospora anserina. Genetics 2009, 182, 69-78. [CrossRef]

16. Carmona-Gutierrez, D.; Bauer, M.A.; Zimmermann, A.; Aguilera, A.; Austriaco, N.; Ayscough, K.; Balzan, R.; Bar-Nun, S.; Barrientos, A.; Belenky, P.; et al. Guidelines and recommendations on yeast cell death nomenclature. Microb. Cell 2018, 5, 4-31. [CrossRef]

17. Brust, D.; Hamann, A.; Osiewacz, H.D. Deletion of PaAif2 and PaAmid2, two genes encoding mitochondrial AIF-like oxidoreductases of Podospora anserina, leads to increased stress tolerance and lifespan extension. Curr. Genet. 2010, 56, 225-235. [CrossRef]

18. Hamann, A.; Brust, D.; Osiewacz, H.D. Deletion of putative apoptosis factors leads to lifespan extension in the fungal ageing model Podospora anserina. Mol. Microbiol. 2007, 65, 948-958. [CrossRef]

19. Minina, E.A.; Staal, J.; Alvarez, V.E.; Berges, J.A.; Berman-Frank, I.; Beyaert, R.; Bidle, K.D.; Bornancin, F.; Casanova, M.; Cazzulo, J.J.; et al. Classification and nomenclature of metacaspases and paracaspases: No more confusion with caspases. Mol. Cell 2020, 77, 927-929. [CrossRef]

20. Strobel, I.; Osiewacz, H.D. Poly(ADP-ribose) polymerase is a substrate recognized by two metacaspases of Podospora anserina. Eukaryot. Cell 2013, 12, 900-912. [CrossRef]

21. Brust, D.; Daum, B.; Breunig, C.; Hamann, A.; Kühlbrandt, W.; Osiewacz, H.D. Cyclophilin D links programmed cell death and organismal aging in Podospora anserina. Aging Cell 2010, 9, 761-775. [CrossRef] [PubMed]

22. Groebe, K.; Krause, F.; Kunstmann, B.; Unterluggauer, H.; Reifschneider, N.H.; Scheckhuber, C.Q.; Sastri, C.; Stegmann, W.; Wozny, W.; Schwall, G.P.; et al. Differential proteomic profiling of mitochondria from Podospora anserina, rat and human reveals distinct patterns of age-related oxidative changes. Exp. Gerontol. 2007, 42, 887-898. [CrossRef]

23. Kramer, P.; Jung, A.T.; Hamann, A.; Osiewacz, H.D. Cyclophilin D is involved in the regulation of autophagy and affects the lifespan of $P$. anserina in response to mitochondrial oxidative stress. Front. Genet. 2016, 7, 165. [CrossRef] [PubMed]

24. Borghouts, C.; Scheckhuber, C.Q.; Stephan, O.; Osiewacz, H.D. Copper homeostasis and aging in the fungal model system Podospora anserina: Differential expression of PaCtr3 encoding a copper transporter. Int. J. Biochem. Cell Biol. 2002, 34, 1355-1371. [CrossRef]

25. Osiewacz, H.D.; Nuber, U. GRISEA, a putative copper-activated transcription factor from Podospora anserina involved in differentiation and senescence. Mol. Gen. Genet. 1996, 252, 115-124. [CrossRef] [PubMed]

26. Prillinger, H.; Esser, K. The phenoloxidases of the ascomycete Podospora anserina. XIII. Action and interaction of genes controlling the formation of laccase. Mol. Gen. Genet. 1977, 156, 333-345. [CrossRef]

27. Averbeck, N.B.; Borghouts, C.; Hamann, A.; Specke, V.; Osiewacz, H.D. Molecular control of copper homeostasis in filamentous fungi: Increased expression of a metallothionein gene during aging of Podospora anserina. Mol. Gen. Genet. 2001, 264, 604-612. [CrossRef]

28. Borghouts, C.; Scheckhuber, C.Q.; Werner, A.; Osiewacz, H.D. Respiration, copper availability and SOD activity in P. anserina strains with different lifespan. Biogerontology 2002, 3, 143-153. [CrossRef]

29. Chatterjee, D.; Kudlinzki, D.; Linhard, V.; Saxena, K.; Schieborr, U.; Gande, S.L.; Wurm, J.P.; Wöhnert, J.; Abele, R.; Rogov, V.V.; et al. Structure and biophysical characterization of the S-adenosylmethionine-dependent O-methyltransferase PaMTH1, a putative enzyme accumulating during senescence of Podospora anserina. J. Biol. Chem. 2015, 290, 16415-16430. [CrossRef]

30. Grimm, C.; Osiewacz, H.D. Manganese rescues adverse effects on lifespan and development in Podospora anserina challenged by excess hydrogen peroxide. Exp. Gerontol. 2015, 63, 8-17. [CrossRef] 
31. Knab, B.; Osiewacz, H.D. Methylation of polyphenols with vicinal hydroxyl groups: A protection pathway increasing organismal lifespan. Cell Cycle 2010, 9, 3387-3388. [CrossRef]

32. Kunstmann, B.; Osiewacz, H.D. The S-adenosylmethionine dependent O-methyltransferase PaMTH1: A longevity assurance factor protecting Podospora anserina against oxidative stress. Aging 2009, 1, 328-334. [CrossRef]

33. Strobel, I.; Breitenbach, J.; Scheckhuber, C.Q.; Osiewacz, H.D.; Sandmann, G. Carotenoids and carotenogenic genes in Podospora anserina: Engineering of the carotenoid composition extends the life span of the mycelium. Curr. Genet. 2009, 55, 175-184. [CrossRef] [PubMed]

34. Zintel, S.; Bernhardt, D.; Rogowska-Wrzesinska, A.; Osiewacz, H.D. PaCATB, a secreted catalase protecting Podospora anserina against exogenous oxidative stress. Aging 2011, 3, 768-781. [CrossRef] [PubMed]

35. Zintel, S.; Schwitalla, D.; Luce, K.; Hamann, A.; Osiewacz, H.D. Increasing mitochondrial superoxide dismutase abundance leads to impairments in protein quality control and ROS scavenging systems and to lifespan shortening. Exp. Gerontol. 2010, 45, 525-532. [CrossRef]

36. Han, D.; Antunes, F.; Canali, R.; Rettori, D.; Cadenas, E. Voltage-dependent anion channels control the release of the superoxide anion from mitochondria to cytosol. J. Biol. Chem. 2003, 278, 5557-5563. [CrossRef] [PubMed]

37. Gredilla, R.; Grief, J.; Osiewacz, H.D. Mitochondrial free radical generation and lifespan control in the fungal aging model Podospora anserina. Exp. Gerontol. 2006, 41, 439-447. [CrossRef]

38. Stumpferl, S.W.; Stephan, O.; Osiewacz, H.D. Impact of a disruption of a pathway delivering copper to mitochondria on Podospora anserina metabolism and life span. Eukaryot. Cell 2004, 3, 200-211. [CrossRef]

39. Kowald, A.; Hamann, A.; Zintel, S.; Ullrich, S.; Klipp, E.; Osiewacz, H.D. A systems biological analysis links ROS metabolism to mitochondrial protein quality control. Mech. Ageing Dev. 2012, 133, 331-337. [CrossRef]

40. Averbeck, N.B.; Jensen, O.N.; Mann, M.; Schägger, H.; Osiewacz, H.D. Identification and characterization of PaMTH1, a putative O-methyltransferase accumulating during senescence of Podospora anserina cultures. Curr. Genet. 2000, 37, 200-208. [CrossRef]

41. Jungbluth, G.; Rühling, I.; Ternes, W. Oxidation of flavonols with $\mathrm{Cu}(\mathrm{II}), \mathrm{Fe}(\mathrm{II})$ and $\mathrm{Fe}(\mathrm{III})$ in aqueous media. J. Chem. Soc. Perkin Trans. 2000, 2, 1946-1952. [CrossRef]

42. Kunstmann, B.; Osiewacz, H.D. Over-expression of an S-adenosylmethionine-dependent methyltransferase leads to an extended lifespan of Podospora anserina without impairments in vital functions. Aging Cell 2008, 7, 651-662. [CrossRef]

43. Sellem, C.H.; Lecellier, G.; Belcour, L. Transposition of a group II intron. Nature 1993, 366, 176-178. [CrossRef]

44. Fassbender, S.; Brühl, K.H.; Ciriacy, M.; Kück, U. Reverse transcriptase activity of an intron encoded polypeptide. EMBO J. 1994, 13, 2075-2083. [CrossRef] [PubMed]

45. Hermanns, J.; Asseburg, A.; Osiewacz, H.D. Evidence for a life span-prolonging effect of a linear plasmid in a longevity mutant of Podospora anserina. Mol. Gen. Genet. 1994, 243, 297-307. [CrossRef]

46. Hermanns, J.; Osiewacz, H.D. The linear mitochondrial plasmid pAL2-1 of a long-lived Podospora anserina mutant is an invertron encoding a DNA and RNA polymerase. Curr. Genet. 1992, 22, 491-500. [CrossRef] [PubMed]

47. Osiewacz, H.D.; Hermanns, J.; Marcou, D.; Triffi, M.; Esser, K. Mitochondrial DNA rearrangements are correlated with a delayed amplification of the mobile intron (plDNA) in a long-lived mutant of Podospora anserina. Mutat Res. 1989, 219, 9-15. [CrossRef]

48. Soerensen, M.; Gredilla, R.; Müller-Ohldach, M.; Werner, A.; Bohr, V.A.; Osiewacz, H.D.; Stevnsner, T. A potential impact of DNA repair on ageing and lifespan in the ageing model organism Podospora anserina: Decrease in mitochondrial DNA repair activity during ageing. Mech. Ageing Dev. 2009, 130, 487-496. [CrossRef] [PubMed]

49. Becker, T.; Böttinger, L.; Pfanner, N. Mitochondrial protein import: From transport pathways to an integrated network. Trends Biochem. Sci. 2012, 37, 85-91. [CrossRef] [PubMed]

50. Young, L.; Leonhard, K.; Tatsuta, T.; Trowsdale, J.; Langer, T. Role of the ABC transporter Mdl1 in peptide export from mitochondria. Science 2001, 291, 2135-2138. [CrossRef] [PubMed]

51. Luce, K.; Osiewacz, H.D. Increasing organismal healthspan by enhancing mitochondrial protein quality control. Nat. Cell Biol. 2009, 11, 852-858. [CrossRef] [PubMed]

52. Adam, C.; Picard, M.; Déquard-Chablat, M.; Sellem, C.H.; Hermann-Le Denmat, S.; Contamine, V. Biological roles of the Podospora anserina mitochondrial Lon protease and the importance of its N-domain. PLoS ONE 2012, 7, e38138. [CrossRef]

53. Kambacheld, M.; Augustin, S.; Tatsuta, T.; Müller, S.; Langer, T. Role of the novel metallopeptidase Mop112 and saccharolysin for the complete degradation of proteins residing in different subcompartments of mitochondria. J. Biol. Chem. 2005, 280, 20132-20139. [CrossRef] [PubMed]

54. Pearce, D.A.; Sherman, F. Degradation of cytochrome oxidase subunits in mutants of yeast lacking cytochrome c and suppression of the degradation by mutation of yme1. J. Biol. Chem. 1995, 270, 20879-20882. [CrossRef]

55. Weil, A.; Luce, K.; Dröse, S.; Wittig, I.; Brandt, U.; Osiewacz, H.D. Unmasking a temperature-dependent effect of the P. anserina i-AAA protease on aging and development. Cell Cycle 2011, 10, 4280-4290. [CrossRef] [PubMed]

56. Haynes, C.M.; Petrova, K.; Benedetti, C.; Yang, Y.; Ron, D. ClpP mediates activation of a mitochondrial unfolded protein response in C. elegans. Dev. Cell 2007, 13, 467-480. [CrossRef] [PubMed]

57. Fischer, F.; Langer, J.D.; Osiewacz, H.D. Identification of potential mitochondrial CLPXP protease interactors and substrates suggests its central role in energy metabolism. Sci. Rep. 2015, 5, 18375. [CrossRef]

58. Szczepanowska, K.; Senft, K.; Heidler, J.; Herholz, M.; Kukat, A.; Höhne, M.N.; Hofsetz, E.; Becker, C.; Kaspar, S.; Giese, H.; et al. A salvage pathway maintains highly functional respiratory complex I. Nat. Commun. 2020, 11, 1643. [CrossRef] [PubMed] 
59. Huang, S.; Petereit, J.; Millar, A.H. Loss of conserved mitochondrial CLPP and its functions lead to different phenotypes in plants and other organisms. Plant Signal. Behav. 2020, 15, 1831789. [CrossRef] [PubMed]

60. Petereit, J.; Duncan, O.; Murcha, M.W.; Fenske, R.; Cincu, E.; Cahn, J.; Pružinská, A.; Ivanova, A.; Kollipara, L.; Wortelkamp, S.; et al. Mitochondrial CLPP2 assists coordination and homeostasis of respiratory complexes. Plant Physiol. 2020, 184, 148-164. [CrossRef] [PubMed]

61. Knuppertz, L.; Osiewacz, H.D. Autophagy compensates impaired energy metabolism in CLPXP-deficient Podospora anserina strains and extends healthspan. Aging Cell 2017, 16, 704-715. [CrossRef]

62. Fischer, F.; Weil, A.; Hamann, A.; Osiewacz, H.D. Human CLPP reverts the longevity phenotype of a fungal ClpP deletion strain. Nat. Commun. 2013, 4, 1397. [CrossRef] [PubMed]

63. Taylor, E.B.; Rutter, J. Mitochondrial quality control by the ubiquitin-proteasome system. Biochem. Soc. Trans. 2011, 39, 1509-1513. [CrossRef]

64. Chondrogianni, N.; Petropoulos, I.; Franceschi, C.; Friguet, B.; Gonos, E.S. Fibroblast cultures from healthy centenarians have an active proteasome. Exp. Gerontol. 2000, 35, 721-728. [CrossRef]

65. Chondrogianni, N.; Gonos, E.S. Proteasome dysfunction in mammalian aging: Steps and factors involved. Exp. Gerontol. 2005, 40, 931-938. [CrossRef] [PubMed]

66. Wiemer, M.; Osiewacz, H.D. The proteasome activity reporter GFP-Cl1 is degraded by autophagy in the aging model Podospora anserina. F1000Res 2014, 3, 230. [CrossRef]

67. Philipp, O.; Hamann, A.; Servos, J.; Werner, A.; Koch, I.; Osiewacz, H.D. A genome-wide longitudinal transcriptome analysis of the aging model Podospora anserina. PLoS ONE 2013, 8, e83109. [CrossRef]

68. Knuppertz, L.; Warnsmann, V.; Hamann, A.; Grimm, C.; Osiewacz, H.D. Stress-dependent opposing roles for mitophagy in aging of the ascomycete Podospora anserina. Autophagy 2017, 13, 1037-1052. [CrossRef] [PubMed]

69. Knuppertz, L.; Hamann, A.; Pampaloni, F.; Stelzer, E.; Osiewacz, H.D. Identification of autophagy as a longevity-assurance mechanism in the aging model Podospora anserina. Autophagy 2014, 10, 822-834. [CrossRef] [PubMed]

70. Meyer, N.; Zielke, S.; Michaelis, J.B.; Linder, B.; Warnsmann, V.; Rakel, S.; Osiewacz, H.D.; Fulda, S.; Mittelbronn, M.; Münch, C.; et al. AT 101 induces early mitochondrial dysfunction and HMOX1 (heme oxygenase 1) to trigger mitophagic cell death in glioma cells. Autophagy 2018, 14, 1693-1709. [CrossRef] [PubMed]

71. Warnsmann, V.; Osiewacz, H.D. Curcumin treatment affects mitochondrial respiration, induces autophagy and increases lifespan of the fungal aging model Podospora anserina. Endocytobiosis Cell Res. 2016, 27, 20-26.

72. Heinz, D.; Krotova, E.; Hamann, A.; Osiewacz, H.D. Simultaneous ablation of the catalytic AMPK $\alpha$-subunit SNF1 and mitochondrial matrix protease CLPP results in pronounced lifespan extension. Front. Cell Dev. Biol. 2021, 9, 616520. [CrossRef]

73. Contamine, V.; Zickler, D.; Picard, M. The Podospora rmp1 gene implicated in nucleus-mitochondria cross-talk encodes an essential protein whose subcellular location is developmentally regulated. Genetics 2004, 166, 135-150. [CrossRef]

74. Sellem, C.H.; Lemaire, C.; Lorin, S.; Dujardin, G.; Sainsard-Chanet, A. Interaction between the oxa1 and rmp1 genes modulates respiratory complex assembly and life span in Podospora anserina. Genetics 2005, 169, 1379-1389. [CrossRef]

75. Henkel, V.; Schürmanns, L.; Brunner, M.; Hamann, A.; Osiewacz, H.D. Role of sorting nexin PaATG24 in autophagy, aging and development of Podospora anserina. Mech. Ageing Dev. 2020, 186, 111211. [CrossRef]

76. Haft, C.R.; de la Luz Sierra, M.; Barr, V.A.; Haft, D.H.; Taylor, S.I. Identification of a family of sorting nexin molecules and characterization of their association with receptors. Mol. Cell Biol. 1998, 18, 7278-7287. [CrossRef] [PubMed]

77. Nice, D.C.; Sato, T.K.; Stromhaug, P.E.; Emr, S.D.; Klionsky, D.J. Cooperative binding of the cytoplasm to vacuole targeting pathway proteins, Cvt13 and Cvt20, to phosphatidylinositol 3-phosphate at the pre-autophagosomal structure is required for selective autophagy. J. Biol. Chem. 2002, 277, 30198-30207. [CrossRef]

78. Leprince, C.; Le Scolan, E.; Meunier, B.; Fraisier, V.; Brandon, N.; De Gunzburg, J.; Camonis, J. Sorting nexin 4 and amphiphysin 2, a new partnership between endocytosis and intracellular trafficking. J. Cell Sci. 2003, 116, 1937-1948. [CrossRef] [PubMed]

79. Scheckhuber, C.Q.; Erjavec, N.; Tinazli, A.; Hamann, A.; Nyström, T.; Osiewacz, H.D. Reducing mitochondrial fission results in increased life span and fitness of two fungal ageing models. Nat. Cell Biol. 2007, 9, 99-105. [CrossRef]

80. Figge, M.T.; Reichert, A.S.; Meyer-Hermann, M.; Osiewacz, H.D. Deceleration of fusion-fission cycles improves mitochondrial quality control during aging. PLoS Comput. Biol. 2012, 8, e1002576. [CrossRef]

81. Figge, M.T.; Osiewacz, H.D.; Reichert, A.S. Quality control of mitochondria during aging: Is there a good and a bad side of mitochondrial dynamics? Bioessays 2013, 35, 314-322. [CrossRef] [PubMed]

82. Mohanraj, K.; Nowicka, U.; Chacinska, A. Mitochondrial control of cellular protein homeostasis. Biochem. J. 2020, 477, 3033-3054. [CrossRef] [PubMed]

83. Wiedemann, N.; Pfanner, N. Mitochondrial machineries for protein import and assembly. Annu. Rev. Biochem. 2017, 86, 685-714. [CrossRef] [PubMed]

84. Daum, B.; Walter, A.; Horst, A.; Osiewacz, H.D.; Kühlbrandt, W. Age-dependent dissociation of ATP synthase dimers and loss of inner-membrane cristae in mitochondria. Proc. Natl. Acad. Sci. USA 2013, 110, 15301-15306. [CrossRef] [PubMed]

85. Scheckhuber, C.Q.; Grief, J.; Boilan, E.; Luce, K.; Debacq-Chainiaux, F.; Rittmeyer, C.; Gredilla, R.; Kolbesen, B.O.; Toussaint, O.; Osiewacz, H.D. Age-related cellular copper dynamics in the fungal ageing model Podospora anserina and in ageing human fibroblasts. PLoS ONE 2009, 4, e4919. [CrossRef] [PubMed] 
86. Boilan, E.; Winant, V.; Dumortier, E.; Piret, J.P.; Bonfitto, F.; Osiewacz, H.D.; Debacq-Chainiaux, F.; Toussaint, O. Role of p38MAPK and oxidative stress in copper-induced senescence. Age (Dordr) 2013, 35, 2255-2271. [CrossRef]

87. Rampello, N.G.; Stenger, M.; Westermann, B.; Osiewacz, H.D. Impact of F1Fo-ATP-synthase dimer assembly factors on mitochondrial function and organismic aging. Microb. Cell 2018, 5, 198-207. [CrossRef]

88. Pfeiffer, K.; Gohil, V.; Stuart, R.A.; Hunte, C.; Brandt, U.; Greenberg, M.L.; Schägger, H. Cardiolipin stabilizes respiratory chain supercomplexes. J. Biol. Chem. 2003, 278, 52873-52880. [CrossRef] [PubMed]

89. Arnarez, C.; Marrink, S.J.; Periole, X. Molecular mechanism of cardiolipin-mediated assembly of respiratory chain supercomplexes. Chem. Sci. 2016, 7, 4435-4443. [CrossRef]

90. Koepke, J.I.; Wood, C.S.; Terlecky, L.J.; Walton, P.A.; Terlecky, S.R. Progeric effects of catalase inactivation in human cells. Toxicol. Appl. Pharmacol. 2008, 232, 99-108. [CrossRef]

91. Legakis, J.E.; Koepke, J.I.; Jedeszko, C.; Barlaskar, F.; Terlecky, L.J.; Edwards, H.J.; Walton, P.A.; Terlecky, S.R. Peroxisome senescence in human fibroblasts. Mol. Biol. Cell 2002, 13, 4243-4255. [CrossRef]

92. Koepke, J.I.; Nakrieko, K.A.; Wood, C.S.; Boucher, K.K.; Terlecky, L.J.; Walton, P.A.; Terlecky, S.R. Restoration of peroxisomal catalase import in a model of human cellular aging. Traffic 2007, 8, 1590-1600. [CrossRef]

93. Kionka, C.; Kunau, W.-H. Inducible beta-oxidation pathway in Neurospora crassa. J. Bacteriol. 1985, 161, 153-157. [CrossRef]

94. Kunau, W.-H.; Kionka, C.; Ledebur, A.; Mateblowski, M.; Moreno de la Garza, M.; Schultz-Borchard, U.; Thieringer, R.; Veenhuis, M. microorganisms. In Peroxisomes in Biology And Medicine; Fahimi, H.D., Sies, H., Eds.; Springer: Berlin/Heidelberg, Germany, 1987; pp. 128-140.

95. Thieringer, R.; Kunau, W.H. The beta-oxidation system in catalase-free microbodies of the filamentous fungus Neurospora crassa. Purification of a multifunctional protein possessing 2-enoyl-CoA hydratase, L-3-hydroxyacyl-CoA dehydrogenase, and 3-hydroxyacyl-CoA epimerase activities. J. Biol. Chem. 1991, 266, 13110-13117. [CrossRef]

96. Bourdais, A.; Bidard, F.; Zickler, D.; Berteaux-Lecellier, V.; Silar, P.; Espagne, E. Wood utilization is dependent on catalase activities in the filamentous fungus Podospora anserina. PLoS ONE 2012, 7, e29820. [CrossRef] [PubMed]

97. Goldfischer, S.; Moore, C.L.; Johnson, A.B.; Spiro, A.J.; Valsamis, M.P.; Wisniewski, H.K.; Ritch, R.H.; Norton, W.T.; Rapin, I.; Gartner, L.M. Peroxisomal and mitochondrial defects in the cerebro-hepato-renal syndrome. Science 1973, 182, 62-64. [CrossRef] [PubMed]

98. Bonnet, C.; Espagne, E.; Zickler, D.; Boisnard, S.; Bourdais, A.; Berteaux-Lecellier, V. The peroxisomal import proteins PEX2, PEX5 and PEX7 are differently involved in Podospora anserina sexual cycle. Mol. Microbiol. 2006, 62, 157-169. [CrossRef] [PubMed]

99. Bleazard, W.; McCaffery, J.M.; King, E.J.; Bale, S.; Mozdy, A.; Tieu, Q.; Nunnari, J.; Shaw, J.M. The dynamin-related GTPase Dnm1 regulates mitochondrial fission in yeast. Nat. Cell Biol. 1999, 1, 298-304. [CrossRef]

100. Motley, A.M.; Ward, G.P.; Hettema, E.H. Dnm1p-dependent peroxisome fission requires Caf4p, Mdv1p and Fis1p. J. Cell Sci. 2008, 121, 1633-1640. [CrossRef] [PubMed]

101. Motley, A.M.; Hettema, E.H. Yeast peroxisomes multiply by growth and division. J. Cell Biol. 2007, 178, 399-410. [CrossRef]

102. Farré, J.C.; Mahalingam, S.S.; Proietto, M.; Subramani, S. Peroxisome biogenesis, membrane contact sites, and quality control. EMBO Rep. 2019, 20. [CrossRef]

103. Pomatto, L.C.; Raynes, R.; Davies, K.J. The peroxisomal Lon protease LonP2 in aging and disease: Functions and comparisons with mitochondrial Lon protease LonP1. Biol. Rev. Camb. Philos. Soc. 2017, 92, 739-753. [CrossRef]

104. Peraza-Reyes, L.; Zickler, D.; Berteaux-Lecellier, V. The peroxisome RING-finger complex is required for meiocyte formation in the fungus Podospora anserina. Traffic 2008, 9, 1998-2009. [CrossRef] [PubMed]

105. Takano-Rojas, H.; Zickler, D.; Peraza-Reyes, L. Peroxisome dynamics during development of the fungus Podospora anserina. Mycologia 2016, 108, 590-602. [CrossRef] [PubMed] 